\title{
Risk Factors for Endometrioid, Mucinous and Serous Benign Ovarian Cysts
}

\author{
FABIO PARAZZINI", CARLO LA VECCHIA* **, SILVIA FRANCESCHI ${ }^{\dagger}$ EVA NEGRI ${ }^{\ddagger}$ \\ AND GABRIELA CECCHETT'
}

\begin{abstract}
Parazzini F (Mario Negri Institute for Pharmacological Research, Via Eritrea 62, 20157 Milan, ttaly), La Vecchia C, Franceschi S, Negri E and Cecchettil G. Risk factors for endometrioid, mucinous and serous benign ovarian cysts. International Journal of Epidemiology 1989, 18: 108-112.

To evaluate the risk factors for serous, mucinous and endometrioid ovarian cysts, data were collected in a casecontrol study conducted in the greater Milan area based on 202 women with benign cysts (114 endometrioid and 88 serous or mucinous) of the ovary and 1127 controls. Questions were asked about menstrual and reproductive characteristics, marital status, education, history of various diseases, and lifetime use of oral contraceptives and other hormonal treatments. Higher social class, earlier menarche and longer interval between age at first marriage and first birth, a likely indicator of subfertility, were associated with an increased risk of serous, mucinous and endometrioid cysts. Women with endometrioid cyst were characterized by low parity, less frequent irregular or long menses, more frequent oral contraceptive use and low body mass index, while the most relevant risk factor associated with serous and mucinous cysts was greater age at first birth. The present data point out the epidemiological differences between endometrioid and serous or mucinous cysts. Further, they suggest that analyses of risk factors for epithelial ovarian cancer subdivided by various histotypes may be of interest in order to confirm possible heterogeneities in the aetiology of ovarian epithelial neoplasms.
\end{abstract}

Benign ovarian cysts are one of the most common surgical conditions in young women and, thus, represent per se a relevant public health problem. The common origin from the surface epithelium of the ovary (which is the direct descendant of the coelomic epithelium, or mesothelium of the embryonic gonadal ridge) suggests that malignant and benign ovarian neoplasms may share similar aetiological profiles. The mesothelium could develop, through a metaplastic mechanism, into cystoadenomas or adenocarcinomas with mucinous, serous and endometrioid histological appearance.

Epidemiological evidence on benign ovarian cysts is still scanty and largely controversial. For example, conflicting results have been reported on oral contraceptive (OC) use (a known protective factor for ovarian cancer), suggesting a protective effect on functional cysts, ' but no consistent association with cystoadenomas. ${ }^{2.3}$ Clinical reports indicate that endometrioid ovarian cysts cause specific signs and symptoms, such as reproductive failure (sterility or reduced fertility) and

\footnotetext{
* 'Mario Negri' Institute for Pharmacological Research, Via Eritrea 62, 20157 Milan, Italy.

* Institute of Social and Preventive Medicine, University of Lausanne, 1005 Lausanne, Switzerland.

† Oncological Referral Center, 33081 Aviano, Pordenone, Italy.

\# Inter-University Consortium of Lombardy for Automatic Data Processing, 20090 Segrate, Milan, Italy.

S 3rd Obstetrics and Gynecology Clinic of the University of Milan, 20129 Milan, Italy.
}

chronic pelvic pain. These different clinical appearances are not totally explained in the light of aetiological hypotheses. In fact, besides the metaplastic mechanism, various other theories have been proposed to explain the development of ovarian and, more in general, pelvic endometriosis, such as implantation of endometrial tissue or metastatic-like spread through blood/lymphatic vessels. ${ }^{4}$

To assess the epidemiological features of benign ovarian cysts as an overall clinical entity and their specific histological subgroups, we have considered data from a hospital case-control study conducted in the greater Milan area, northern Italy.

\section{SUBJECTS AND METHODS}

Within the framework of a case-control surveillance on breast and female genital tract neoplasms conducted in the greater Milan area (whose general design has previously been described ${ }^{5}$ ), we started data collection on benign ovarian disease in January 1984 .

Trained interviewers identified and questioned cases and controls admitted to University and general hospitals in the greater Milan area. On average, less than $2 \%$ of eligible women refused to be interviewed. A standard questionnaire was used to obtain information on personal characteristics and habits, gynaecological and obstetric data, related medical history and history of lifetime use of oral contraceptives and other female hormones. The present report is based on data collected until June 1986.

Cases: The study cases were women admitted to the 
1st and 3rd Obstetrics and Gynaecology Clinic of the University of Milan with histologically confirmed diagnosis of epithelial ovarian cyst. Functional (follicular and luteal) cysts and benign teratomas were excluded. After review of the pathological material by the same pathologist, 40 cases were classified as serous, 48 as mucinous and 114 as endometrioid. For analysis purposes serous and mucinous cysts were grouped together. The age range was $20-68$ years (median age $=35$ years).

Controls: Patients admitted for acute conditions to the Ospedale Maggiore of Milan (which includes the four largest hospitals in Milan) and to several specialized University clinics were eligible as controls. Women were not included if they were admitted for gynaecological, hormonal or neoplastic disease, or had undergone bilateral oophorectomy.

A total of 1127 controls aged 25 to 69 years (median age $=53$ years) were interviewed. Of these $30 \%$ were admitted for traumatic conditions (mostly fractures and sprains), $27 \%$ had non-traumatic orthopaedic disorders (mostly low back pain and disc disorders), 14\% surgical conditions (mostly abdominal, such as acute appendicitis or strangulated hernia) and $29 \%$ had other illnesses, such as ear, nose and throat or teeth disorders. The age distribution of cases and controls is reported in Table 1.

Data analysis: We computed the relative risks of serous or mucinous cysts and ovarian endometriosis, together with their $95 \%$ approximate confidence intervals (CI) ${ }^{6}$ from data stratified for quinquennia of age by the Mantel-Haenszel procedure. ${ }^{7}$ When a factor could be classified in more than two levels, the significance of the linear trend was assessed by the Mantel test. ${ }^{8}$ In the computation of relative risks, the potential confounding effects of age and the major known or potential risk factors for ovarian neoplasms were controlled for using stratification and the Mantel-Haenszel procedure. ${ }^{7}$ However, since adjustment for most covariates did not materially change the estimates, relative risks adjusted for age and education, as indicators of socioeconomic

TABLE 1 Age distribution of 88 serous or mucinous, 114 endometrioid ovarian cysts and 1127 controls. Milan, haly, 1984-1986

\begin{tabular}{|c|c|c|c|c|c|c|}
\hline \multirow{2}{*}{$\begin{array}{l}\text { Age group } \\
\text { (years) }\end{array}$} & \multicolumn{2}{|c|}{$\begin{array}{l}\text { Serous or } \\
\text { mucinous } \\
\text { cysts }\end{array}$} & \multicolumn{2}{|c|}{$\begin{array}{l}\text { Endometrioid } \\
\text { cysts }\end{array}$} & \multicolumn{2}{|c|}{ Controls } \\
\hline & No & $\%$ & No & $\%$ & No & $\%$ \\
\hline$<30$ & 33 & 37.5 & 39 & 34.2 & 42 & 3.7 \\
\hline $30-39$ & 20 & 22.7 & 40 & 35.1 & 146 & 13.0 \\
\hline $40-49$ & 14 & 15.9 & 28 & 24.6 & 235 & 20.9 \\
\hline $50-59$ & 6 & 6.8 & 6 & 5.3 & 341 & 30.3 \\
\hline $60-69$ & 15 & 17.0 & 1 & 0.9 & 363 & 32.2 \\
\hline
\end{tabular}

status, were chosen for presentation, unless otherwise indicated.

\section{RESULTS}

Compared with nulliparous women, the risk of ovarian cysts among parous women decreased with increasing number of births, the point estimates being 0.7 for women with one or two and 0.6 for those with three or more births (Table 2). The trend in risk was significant for the whole series, but when the analysis was conducted separately for serous or mucinous and endometrioid ovarian cysts, this trend appeared to be restricted to endometrioid lesions. Conversely, among parous women, an increased risk of serous or mucinous cysts was observed with increasing age at first birth, whereas no effect emerged on endometrioid cysts (Table 2).

The effect of parity was analysed in separate strata of age at first birth and vice-versa. Compared to nulliparous women, the risk of ovarian cysts was largely below unity in women who had their first birth before age 23 and close to unity in the other strata. A similar trend was observed when the analysis was limited to endometrioid cysts. In relation to age at first birth the risk of serous or mucinous cysts increased in women who had first birth at age 29 or later, independently of the number of births (data not shown).

There was no relation between number of miscarriages and ovarian cysts. A significantly decreased frequency of induced abortions was however observed in women with ovarian endometriosis (Table 3).

Relative to women whose menarche occurred at age 12 or younger, the risk of ovarian cysts was lower for

TABLE 2 Relative risks of benign ovarian cysts according to parity and age at first birh. Milan, Italy, 1984-1986

\begin{tabular}{|c|c|c|c|}
\hline & $\begin{array}{l}\text { Serous or } \\
\text { mucinous } \\
\text { cysts }\end{array}$ & $\begin{array}{l}\text { Endometrioid } \\
\text { cysts }\end{array}$ & Total \\
\hline \multicolumn{4}{|l|}{ Parityt } \\
\hline 0 & $1^{5}(41)^{4}$ & $1^{5} \quad(58)$ & Is $^{\text {s }}$ (99) \\
\hline $1-2$ & $0.6(33)$ & $0.6(49)$ & $0.7(82)$ \\
\hline 23 & 0.9 (14) & $0.3(7)$ & $0.6(21)$ \\
\hline$X_{1}^{2}$ for trend & 1.95 & $8.2 * *$ & $4.55^{*}$ \\
\hline \multicolumn{4}{|c|}{ Age at first birth } \\
\hline$\leq 22$ & $1^{5}$ (11) & $1^{\text {s }}(19)$ & $1^{5} \quad(30)$ \\
\hline $23-28$ & $1.8(26)$ & $1.0(30)$ & $1.4(56)$ \\
\hline 229 & $2.2(10)$ & $1.0 \quad(7)$ & $1.5(17)$ \\
\hline$X_{1}^{2}$ for trend & $4.96^{*}$ & 0.01 & $2.79^{\circ}$ \\
\hline
\end{tabular}

+ Adjusted for age, education and age at first birth.

₹ Adjusted for age, education and parity.

S Reference category.

" The number of cases in each group is shown in parentheses.

* $\mathrm{p}<0.05$.

** $\mathrm{p}<0.01$ 
TABLE 3 Relative riskst of benign ovarian cysts according to previous history of spontaneous or induced abortions. Milan. Italy, 1984-1986

\begin{tabular}{|c|c|c|c|}
\hline Risk factor & $\begin{array}{l}\text { Serous or } \\
\text { mucinous } \\
\text { cysts }\end{array}$ & $\begin{array}{l}\text { Endometrioid } \\
\text { cysts }\end{array}$ & Total \\
\hline \multicolumn{4}{|c|}{ Spontaneous abortions } \\
\hline 0 & $1^{5}(74)^{*}$ & $1^{5} \quad(99)$ & $1^{5}(173)$ \\
\hline$\sum_{(95 \% \mathrm{CI})}^{21}$ & $\begin{array}{l}1.3(14) \\
(0.7-2.6)\end{array}$ & $\begin{array}{c}1.0(15) \\
(0.5-1.7)\end{array}$ & $\begin{array}{l}1.1(29) \\
(0.7-1.9)\end{array}$ \\
\hline \multicolumn{4}{|c|}{ Induced abortions } \\
\hline 0 & $1^{5} \quad(77)$ & $1^{5}(106)$ & $1^{5}(183)$ \\
\hline$\underset{(95 \% \mathrm{CI})}{21}$ & $\begin{array}{cc}1.1 & (11) \\
(0.5-2.3)\end{array}$ & $\begin{array}{l}0.5 \quad(8) \\
(0.2-1.0)\end{array}$ & $\begin{array}{cc}0.7 & (19) \\
(0.4-1.3)\end{array}$ \\
\hline \multicolumn{4}{|c|}{ Total abortions } \\
\hline 0 & 1s (64) & $1^{5} \quad(92)$ & $1^{\text {s }}(156)$ \\
\hline 1 & 1.1 (14) & 1.0 (17) & 1.1 (31) \\
\hline 22 & 1.1 (10) & $0.4 \quad(5)$ & 0.7 (15) \\
\hline$X_{1}^{2}$ for trend & 0.64 & 1.93 & 0.70 \\
\hline
\end{tabular}

+ Adjusted for age, education and number of pregnancies.

s Reference category.

* The number of cases in each group is shown in parentheses.

$\mathrm{CI}$ indicates confidence interval.

those who experienced later menarche. This trend was significant in the serous or mucinous subgroup, whereas for endometriod cysts a protective effect was apparently confined to women who experienced menarche at age 15 or older. Women with menstrual irregularities (simply defined as frequent menstrual-like episodes of bleeding less than 21 or more than 35 days apart) experienced a significantly reduced risk of ovarian cysts $(R R=0.5$, $95 \% \mathrm{CI}=0.3-0.8$ ); this finding was confined only to endometrioid lesions. A more detailed investigation of menstrual cycle patterns confirmed the negative association between totally irregular cycles and ovarian endometriosis and showed, compared with women with cycles of $\mathbf{3 0}$ days or less, a hint of decreased risk for women with regular cycles lasting more than 31 days $(\mathrm{RR}=0.7,95 \% \mathrm{CI}=0.3-1.7$, Table 4). Women with ovarian endometriosis had used oral contraceptives more frequently than controls $(\mathrm{RR}=2.1,95 \% \mathrm{CI}=1.2-3.6)$. Further, the risk of endometriosis increased with duration of oral contraceptive use and with years since last use. Use of intrauterine devices had no observed effect (Table 5).

Cases and controls were similar with reference to various demographic indicators and general characteristics and habits, including marital status and age at first marriage (Table 6). The risk of ovarian cysts increased with longer interval between date of marriage and age at first livebirth; this trend was statistically significant. This finding was evident in both histological subgroups, although it was of only borderline statistical significance in the endometrioid one. Cases had
TABLE 4 Relative riskst of benign ovarian cysts according to age at menarche and menstrual characteristics. Milan, Italy, 1984-1986

\begin{tabular}{|c|c|c|c|}
\hline Risk factor & $\begin{array}{l}\text { Serous or } \\
\text { mucinous } \\
\text { cysts }\end{array}$ & $\begin{array}{c}\text { Endometrioid } \\
\text { cysts }\end{array}$ & Total \\
\hline \multicolumn{4}{|l|}{ Age at menarche } \\
\hline$\leq 12$ & $1^{5}(50)^{*}$ & $1^{5} \quad(55)$ & $1^{s}(105)$ \\
\hline $13-14$ & $0.7(32)$ & $1.1(51)$ & $0.8(83)$ \\
\hline 215 & $0.4 \quad 6)$ & $0.4 \quad(8)$ & 0.4 (14) \\
\hline$X_{1}^{2}$ for trend & $6.43^{*}$ & 1.08 & $5.62^{*}$ \\
\hline \multicolumn{4}{|c|}{ Lifelong menstrual pattern } \\
\hline Regular & $1^{\text {s }} \quad(67)$ & $1^{5}(101)$ & $1^{5}(168)$ \\
\hline Irregular & $0.9 \quad(21)$ & 0.3 (13) & $0.5(34)$ \\
\hline$(95 \% \mathrm{CI})$ & $(0.5-1.7)$ & $(0.2-0.7)$ & $(0.3-0.8)$ \\
\hline \multicolumn{4}{|c|}{ Duration of menstrual cycles (days) } \\
\hline$\leq 30$ & $1^{5}(67)$ & $1^{s}(101)$ & $1^{\text {s }}(168)$ \\
\hline 231 & $0.9(10)$ & 0.7 (11) & $0.7 \quad(21)$ \\
\hline$(95 \% \mathrm{CI})$ & $(0.3-2.2)$ & $(0.3-1.7)$ & $(0.3-1.5)$ \\
\hline $\begin{array}{l}\text { Totally irregular } \\
(95 \% \text { CI) }\end{array}$ & $\begin{array}{c}1.4 \quad(11) \\
(0.6-2.9)\end{array}$ & $\begin{array}{cr}0.1 & (2) \\
(0.1 & -0.4)\end{array}$ & $\begin{array}{c}0.6 \quad(13) \\
(0.3-1.3)\end{array}$ \\
\hline
\end{tabular}

+ Adjusted for age and education.

$s$ Reference category.

" The number of cases in each group is shown in parentheses.

* $\mathrm{p}<0.05$.

$\mathrm{CI}$ indicates confidence interval.

TABLE 5 Relative riskst of benign ovarian cysts according to use of oral contraceptives and intra-uterine devices (IUD). Milan, Italy, $1984-1986$

\begin{tabular}{|c|c|c|c|}
\hline Risk factor & $\begin{array}{c}\text { Serous or } \\
\text { mucinous } \\
\text { cysts }\end{array}$ & $\begin{array}{c}\text { Endometrioid } \\
\text { cysts }\end{array}$ & Total \\
\hline \multicolumn{4}{|c|}{ Oral contraceptive use } \\
\hline Ever used & & & \\
\hline No & $1^{5} \quad(71)^{*}$ & $15 \quad(73)$ & $1^{s}(144)$ \\
\hline Yes & 1.0 (17) & $2.1(41)$ & $1.6(58)$ \\
\hline$(95 \% \mathrm{CI})$ & $(0.5-2.0)$ & $(1.2-3.6)$ & $(1.0-2.6)$ \\
\hline \multicolumn{4}{|c|}{ Duration of use (years) } \\
\hline$\leq 2$ & 1.1 (13) & $1.8(25)$ & $1.6(38)$ \\
\hline$>2$ & $0.9 \quad$ (4) & 2.7 (16) & $1.8(20)$ \\
\hline$X_{1}^{2}$ for trend & 0.00 & $7.48 *$ & $4.01^{*}$ \\
\hline \multicolumn{4}{|c|}{ Time since last use (years) } \\
\hline$<5$ & $0.4 \quad(6)$ & $1.3(14)$ & $0.9(20)$ \\
\hline 25 & $1.1 \quad(9)$ & $2.2(22)$ & $1.8 \quad(31)$ \\
\hline \multicolumn{4}{|l|}{ IUD use } \\
\hline Never & $1^{5} \quad(83)$ & $1^{\text {s }}(109)$ & $1^{\text {s }}(192)$ \\
\hline $\begin{array}{c}\text { Ever } \\
(95 \% \mathrm{CI})\end{array}$ & $\begin{array}{lr}0.6 & (5) \\
(0.2-17)\end{array}$ & $1.0 \quad(5)$ & $0.8 \quad(10)$ \\
\hline
\end{tabular}

+ Adjusted for age and education.

$s$ Reference category.

- The number of cases in each group is shown in parentheses; in some cases, the number in various strata do not add up to the total owing to a few missing values.

$\mathrm{Cl}$ indicates confidence interval.

$* \mathrm{p}<0.01$.

$* \mathrm{p}<0.05$ 
significantly more education than the control group, the risk of ovarian cysts being increased twofold in women with high school or university degree compared with less educated ones. Similarly, cases were of higher social class (Table 6).

Body mass, expressed by the Quetelet's index $\left(\mathrm{Kg} / \mathrm{m}^{2}\right)$, was inversely related to risk of ovarian

TABLE 6 Relative riskst of benign ovarian cysts according to selected general characteristics and habits. Milan, Italy, 1984-1986

\begin{tabular}{|c|c|c|c|}
\hline Risk factor & $\begin{array}{l}\text { Serous or } \\
\text { mucinous } \\
\text { cysts }\end{array}$ & $\begin{array}{l}\text { Endometrioid } \\
\text { cysts }\end{array}$ & Total \\
\hline $\begin{array}{l}\text { Marital status } \\
\text { Never married } \\
\text { Ever married } \\
(95 \% \mathrm{CI})\end{array}$ & $\begin{array}{l}1^{5}(31) \# \\
1.1(57) \\
(0.6-2.2)\end{array}$ & $\begin{array}{c}1^{5}(30) \\
0.6(84) \\
(0.3-1.0)\end{array}$ & $\begin{array}{c}1^{5}(61) \\
0.7(141) \\
(0.4-1.2)\end{array}$ \\
\hline $\begin{array}{l}\text { Age at first marriag } \\
\leq 24 \\
25-29 \\
\geq 30 \\
X_{1}^{2} \text { for trend }\end{array}$ & $\begin{array}{l}\text { ge } \\
1^{\text {s }}(37) \\
1.3(18) \\
0.5 \quad(2) \\
0.00\end{array}$ & $\begin{array}{l}15 \quad(58) \\
1.0(20) \\
1.0(6) \\
0.09\end{array}$ & $\begin{array}{l}15 \quad(95) \\
1.1(38) \\
0.7 \quad(8) \\
0.16\end{array}$ \\
\hline $\begin{array}{l}\text { Interval between ag } \\
\text { and age at first live } \\
\text { Before marriage } \\
<2 \\
2-3 \\
>3 \\
X_{1}^{2} \text { for trend }\end{array}$ & $\begin{array}{l}\text { ge at first ma } \\
\text { ebirth (years) } \\
1.8(2) \\
1^{\text {s }(19)} \\
1.6(18) \\
2.3(8) \\
5.05^{*}\end{array}$ & $\begin{array}{l}1^{5}(30) \\
0.7(14) \\
2.1(12) \\
3.71\end{array}$ & $\begin{array}{l}0.6 \quad(2) \\
1^{\$}(49) \\
1.0(32) \\
2.2(20) \\
7.92 * *\end{array}$ \\
\hline $\begin{array}{l}\text { Education (years) } \\
\quad<6 \\
7-11 \\
\geq 12 \\
X_{1}^{2} \text { for trend }\end{array}$ & $\begin{array}{l}1^{5}(25) \\
1.8(32) \\
1.7(30) \\
5.22^{*}\end{array}$ & $\begin{array}{l}1^{5}(31) \\
1.3(37) \\
1.9(45) \\
6.71^{* *}\end{array}$ & $\begin{array}{l}1^{5}(56) \\
1.5(69) \\
1.8(75) \\
9.14^{* *}\end{array}$ \\
\hline $\begin{array}{l}\text { Social class }^{b} \\
\text { IV or V (lowest) } \\
\text { III } \\
\text { I or II (highest) } \\
\text { Undefined } \\
\mathrm{X}_{\text {I for trend }}^{2}\end{array}$ & $\begin{array}{l}1^{5}(11) \\
1.4(36) \\
1.9(22) \\
-(19) \\
5.41^{*}\end{array}$ & $\begin{array}{l}15(28) \\
1.8(55) \\
1.9(16) \\
-\quad(15) \\
4.92^{*}\end{array}$ & $\begin{array}{l}15 \quad(39) \\
1.6(91) \\
1.8(38) \\
-\quad(34) \\
5.30^{*}\end{array}$ \\
\hline $\begin{array}{l}\text { Body mass index ( } \\
<20 \\
20-25 \\
>25 \\
X_{1}^{2} \text { for trend }\end{array}$ & 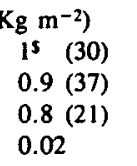 & $\begin{array}{l}1^{5} \quad(39) \\
0.9(63) \\
0.4(12) \\
5.39^{*}\end{array}$ & $\begin{array}{l}1^{5}(69) \\
0.9(100) \\
0.6(33) \\
3.08\end{array}$ \\
\hline $\begin{array}{l}\text { Smoking habits } \\
\text { Never smoked } \\
\text { Ever smoked } \\
(95 \% \mathrm{CI})\end{array}$ & $\begin{array}{c}1^{5}(53) \\
0.9(35) \\
(0.5-1.5)\end{array}$ & $\begin{array}{c}1^{5}(65) \\
1.0(49) \\
(0.6-1.5)\end{array}$ & $\begin{array}{c}1^{5}(118) \\
1.0(84) \\
(0.7-1.2)\end{array}$ \\
\hline
\end{tabular}

t Adjusted for age and education.

s Reference category.

* The number of cases in each group is shown in parentheses; in some cases the number in various strata do not add up to the total owing to a few missing values.

$\mathrm{CI}$ indicates confidence interval.

$* \mathrm{p}<0.05$.

** $p<0.01$.

adjusted for age only.

b Based on the head of the household's occupation. endometriosis $\left(X_{1}^{2}\right.$ for trend $\left.=5.39 p=0.02\right)$, but little influence was evident on the risk of serous or mucinous cysts. Finally, no difference in smoking habits was observed between cases and controls (Table 6).

\section{DISCUSSION}

The present findings suggest that ovarian cysts as a whole share important epidemiological features with ovarian cancer, chiefly nulliparity or low parity and that, despite some similarities, there are considerable differences in the epidemiology of serous or mucinous and endometrioid ovarian cysts. Women with endometrioid cysts were characterized by low parity, regular menses, more frequent oral contraceptive use and low body mass index, while the main risk factor associated with serous or mucinous ovarian cysts, but apparently not with endometrioid cysts, was greater age at first birth.

These findings could not be simply explained by confounding, since allowing for major potential distorting factors (including indicators of socioeconomic status) did not appreciably change the estimated relative risks. Similarly, selection bias should not be a major problem in this study, since cases and controls were identified in institutions covering broadly comparable catchment areas, and participation rate in the study was almost complete. The referring symptoms covered a broad spectrum of conditions such as ovarian enlargement, sterility, infertility and chronic pelvic pain. Further, only histologically confirmed epithelial cysts were considered, after specific exclusion of functional ovarian cysts, which may be more subject to detection (ie diagnostic) or selection (on socioeconomic or other grounds) bias, and are clearly of small clinical importance.

The proportion of unmarried women was similar among cases and controls and no difference emerged in age at first marriage, but the risk of epithelial ovarian cysts increased with longer interval between first marriage and first birth, an aspecific indicator of subfertility. This finding was common in both histological subgroups, suggesting that reduced fertility is associated with endometrioid and serous or mucinous cysts.

Women with ovarian cysts were more educated and of higher social class than controls. This association has been reported for malignant ovarian disease in various studies, ${ }^{9-10}$ but was not present in Italian data collected using methods and selection criteria similar to those adopted in the present study. "Therefore, the association between socioeconomic status and benign disease should be considered cautiously, since it could be, at least in part, related to greater attention to relatively minor health problems by more educated and upper social class women. A similar explanation has been, for example, suggested for benign breast disease. ${ }^{12}$ 
This study did not show that delayed first pregnancy is associated with an increased risk of endometriosis. This differs from previous suggestions chiefly based on clinical observation. ${ }^{13}$ Rather, the smaller number of pregnancies in women with endometrioid cysts confirms the clinical observation that this condition is frequently associated with sterility, however they did not have an increased risk of spontaneous abortions. This is consistent with a previous report, ${ }^{3}$ which, however, did not distinguish between various histological types of ovarian cystoadenomas.

Women with lifelong irregular menses and menstrual cycles longer than $\mathbf{3 0}$ days were at decreased risk of ovarian endometriosis. This finding is in general agreement with results of a case-control study conducted in the US ${ }^{14}$ and could be related to the implantation hypothesis, since women with these menstrual characteristics may have a decreased probability of menstrual contamination of the pelvis. A role for sex hormones (chiefly oestrogens) in the aetiology of endometriosis has been suggested, ${ }^{15}$ but the present study gives little support for this hypothesis. Irregular menses and higher body mass index, conditions favouring higher levels and availability of unopposed circulating oestrogens were associated with a decreased risk of the disease.

Women with endometrioid cysts had used oral contraceptives more frequently and for longer periods. However, this finding should be cautiously considered because of the possible effect of selection bias, although socioeconomic status was allowed for in all the risk estimates presented. Another bias of potential concern in the present study is related to the possibility that the treatment of clinical symptoms of endometriosis (ie dysmenorrhoea) could per se lead to increased oral contraceptive use. In this study, a special effort was made to collect data referring to contraceptive use before diagnosis (ie we have specifically excluded oral contraceptive use to treat endometriosis). Nonetheless, this bias cannot be totally discarded in a case-control study. Further, no relationship emerged between serous or mucinous cysts (which rarely show such symptoms) and oral contraceptive use.

In conclusion, while the present study confirms the existence of several similarities between risk factors for histologically confirmed benign ovarian cysts and ovarian cancer, it also points out substantial epidemiological differences between various histological subgroups. Thus, the findings of this study, besides giving more detailed information than previously available on the epidemiology of benign ovarian lesions, provide interesting clues for further studies on epithelial ovarian cancer. Few data which subdivide ovarian carcinomas according to histological type exists and the present investigation suggests that specific analyses of various histotypes may help clarify a possible heterogeneity of aetiological factors.

\section{ACKNOWLEDGEMENTS}

This study was conducted within the framework of the CNR (Italian National Research Council) applied projects 'Preventive and Rehabilitative Medicine' (contracts No 85.00487.56 and No 85.00549.56) and 'Oncology' (contract No 85.02209.44) and with a grant in aid from the Lombardy Region Department of Health (Contract No 628-2.3.04). The contributions of the Italian League Against Tumours and of the Italian Association for Research on Cancer, Milan, Italy, are gratefully acknowledged. Data processing and analysis was conducted using the computing facilities of the Inter University Consortium of Lombardy for Automatic Data Processing (CILEA). The authors wish to thank Ms Maria Nigro for editorial assistance.

\section{REFERENCES}

' Ory H. Functional ovarian cysts and oral contraceptives. Negative association confirmed surgically. JAMA 1974; 228: 68-9.

2 Vessey $M$, Doll R, Peto R, Johnson B, Wiggins P. A long-term follow-up study of women using different methods of contraception. An interim report. J Biosoc Sci 1976; 8: 373-427.

${ }^{3}$ Vessey M, Metcalfe A, Wells C, McPherson K, Westhoff C, Yeates D. Ovarian neoplasms, functional ovarian cysts, and oral contraceptives. Br Med J (Clin Res) 1987; 294: 1518-20.

${ }^{4}$ Dmowski W P, Radwanska E. Current concepts on pathology, histogenesis and etiology of endometriosis. Acta Obstet Gynecol Scand 1984; Suppl 123: 29-33.

${ }^{5}$ La Vecchia C, Decarli A, Fasoli M, et al. Oral contraceptives and cancers of the breast and of the female genital tract. Interim results from a case-control study. Br J Cancer 1986; 54: 311-7.

${ }^{6}$ Miettinen $\mathrm{O}$. Estimability and estimation in case-referent studies. Am $J$ Epidemiol 1976; 103: 226-35.

${ }^{7}$ Mantel N, Haenszel W. Statistical aspects of the analysis of data from retrospective studies of disease. $J N C I$ 1959; 22: 719-48.

${ }^{8}$ Mantel N. Chi-square tests for one degree of freedom; extensions of the Mantel-Haenszel procedure. J Am Stat Assoc 1963; 58: 690-700.

${ }^{9}$ Stewart H L, Dunham L J, Casper J, et al. Epidemiology of cancers of uterine cervix and corpus, breast and ovary in Israel and New York City. JNCI 1966; 37: 1-95.

10 Winder E L, Dodo H, Barber H R K, Epidemiology of cancer of the ovary. Cancer 1969; 23: 352-70.

"Franceschi S, La Vecchia C, Helmrich S P, Mangioni C, Tognoni G. Risk factors for epithelial ovarian cancer in Italy. Am J Epidemiol 1982; 115: 714-9.

12 Parazzini F, La Vecchia C, Franceschi S, et al. Risk factors for pathologically confirmed benign breast disease. Am J Epidemiol 1984; 120: 115-22.

${ }^{13}$ Houston D E. Evidence for the risk of pelvic endometriosis by age, race and socioeconomic status. Epidemiol Rev 1984; 6: 167-91.

4. Cramer D W, Wilson E, Stillman R J, et al. The relation of endometriosis to menstrual characteristics, smoking, and exercise. JAMA 1986; 255: 1904-8.

$\checkmark$ Dizerega G S, Barber D L, Hodgen G D. Endometriosis: Role of ovarian steroids in initiation, maintenance, and suppression. Fertil Steril 1980; 33: 649-53.

(Revised version received May 1988) 